\title{
Esferas precolombinas de la zona sur en Costa Rica: cultura y poder en la tecnología de la piedra'
}

\author{
Precolumbian Spheres in Costa Rican south : \\ Culture and Power around stone technology
}

Alexandra De-Simone²

Fecha de recepción: 30 de julio del 2013

Fecha de aprobación: 3 de setiembre del 2013

De-Simone, A. Esferas precolombinas de la zona sur en Costa Rica: cultura y poder en la tecnología de la piedra. Tecnología en Marcha. Número Especial. Pág 70-83. 


\section{Alexandra De Simone}

Profesora universitaria con categoría de Asociada, Escuela de Cultura y Deporte Instituto Tecnológico de Costa Rica (ITCR) y Escuela de Psicología Universidad de Costa Rica. Psicóloga Social con Especialidad en Procesos Grupales institucionales y comunitarios y Metodologías Participativas, enfoque histórico cultural. Actriz y Directora Teatral. Consultora en Proyectos sociales y Cultura, y en Género, Seguridad Ciudadana y Derechos Humanos. Promotora y Gestora en Cultura.

Con 27 años de servicio como académica del ITCR, su labor se ha centrado en la apertura de espacios y servicios culturales. Gestora de la Unidad de Cultura y Deporte del Centro Académico San José, Gestora del Proyecto Casa Cultural Amón, fundadora de los grupos teatrales Agosto (estudiantil universitario) e ITCR, profesional universitario. Directora del Teatro Agosto desde su fundación, hace 26 años, con 29 direcciones teatrales destacando en la depuración del método de creación colectiva para teatro comunitario. Vicepresidenta de la Asamblea Institucional Representativa (período 200I), Reconocimiento como Profesora Destacada de la Vicerrectoría de Docencia del ITCR, Reconocimiento como Mujer Destacada de la Oficina de Equidad de Género del ITCR. Coordinadora de Cultura y Deporte San José en su primer período. Presidenta Asociación Cultural Centro Académico (ACUCASJ).

Cátedras: Artes Dramáticas, Apreciación de Cine, Dinámica de la Cultura. 


\section{Palabras clave}

Esferas; cultura; poder; estética; resistencia

\section{Resumen}

Este artículo pretende articular una reflexión sobre la cultura y el poder, tomando como objeto las esferas producidas por una cultura antigua de América en lo que hoy es la zona sur del territorio costarricense. En la primera parte se describen algunas de las dinámicas simbólicas del poder en las que estos enigmáticos objetos se han visto involucrados: como espectáculo mediático, reforzadores de la identidad nacional u objetos de movilización de una comunidad bananera; además se mencionan los avatares institucionales con relación al patrimonio arqueológico. En la segunda parte se desarrolla un conjunto de notas para el análisis estético interpretativo de las esferas, aplicando categorías de la historiografía crítica a los hallazgos y trabajos recientes de la arqueología de las esferas: encuadre histórico y contextualización (reconstrucción interpretativa, desclasificación, diálogo entre objetos diversos, carácter social de la práctica estética). Se pretende destacar la dinámica trama de significaciones en que las esferas se han visto involucradas a partir del misterio que encierran.

\section{Keywords}

Spheres; culture; power; aesthetic; resistance.

\begin{abstract}
This article seeks to articulate a reflection on culture and power, taking as object the Spheres produced by an ancient culture of America, in what is now the southern of Costa Rican territory. In the first part, we describe some of the symbolic dynamics of power in wich these enigmatic objects have been involved: as media spectacle, as a reinforcer of national identity, as the object of a banana community mobilization, with mention of the institutional problems around archaeological heritage. In the second part, we develop a set of notes for interpretive aesthetic analysis of the spheres, using categories of critical historiography on findings of recent archeology: historical setting and context (interpretive reconstruction, declassification, dialogue between different objects, social character of aesthetic practice). It aims to highlight the dynamic web of meanings in which the Spheres have been involved from the mystery they contain.
\end{abstract}




\section{Punto de partida}

"La lucha de clases, que el historiador educado en Marx tiene siempre presente, es una lucha por las cosas burdas y materiales, sin las cuales no existen las más finas y espirituales. Pero estas últimas están presentes en la lucha de clases, y no como la simple imagen de una presa destinada al vencedor. En tal lucha esas cosas se manifiestan como confianza, valentía, humor, astucia, impasibilidad, y actúan retroactivamente en la lejanía de los tiempos. Ellas pondrán en cuestión toda victoria lograda en el tiempo por los dominadores". Walter Benjamín (2010, p. 6I)

Desde su desamparado hallazgo en lo que sería una plantación bananera, echadas a rodar como ornamentos de jardín, dinamitadas para extraer áureos tesoros, regaladas como curiosidad, objeto de lucha comunitaria contra el despojo, fetiche de magnetismos energéticos y viajes extraterrestres, emblema nacional del papel moneda, embajadoras de la cultura costarricense, promesa de seducción turística, souvenir de artesanía local, inspiradoras de uno de los artistas con mayor reconocimiento internacional, hasta motivo protagónico de resistencia de la defensa institucional del patrimonio ancestral costarricense. El camino de significaciones de las esferas muestra la contradictoria y diversa trama del reconocimiento del valor estético a un producto de la tecnología de la piedra precolombina. Una trama que adquiere sentido en el escenario político, social y económico costarricense de los últimos cincuenta años.

Este artículo busca articular una reflexión sobre la cultura y el poder, tomando como objeto las esferas producidas por una cultura antigua de América en lo que hoy es la zona sur del territorio costarricense. En su primera parte, se describen las dinámicas simbólicas del poder en las que estos enigmáticos objetos se han visto involucrados, en su segunda parte se desarrolla un conjunto de notas para el análisis estético interpretativo, aplicando categorías de la historiografía crítica a los hallazgos y trabajos recientes de la arqueología de las esferas.

Los referentes conceptuales desde los cuales se trabaja este artículo entienden la cultura en su dimensión simbólico-política, como el conjunto de creencias y prácticas que actúan como mundo de significación en el que la conducta de una sociedad debe ser contenida, como horizontes organizadores de sentido, modeladores de identidades/subjetividades (Araujo, 20l0, p. 72). La cultura se revela como lugar de conflicto y de tensión, como tecnología del control, en el que se legitiman los discursos de los grupos hegemónicos, como microfísica del poder según plantea Foucault (1976), en que los

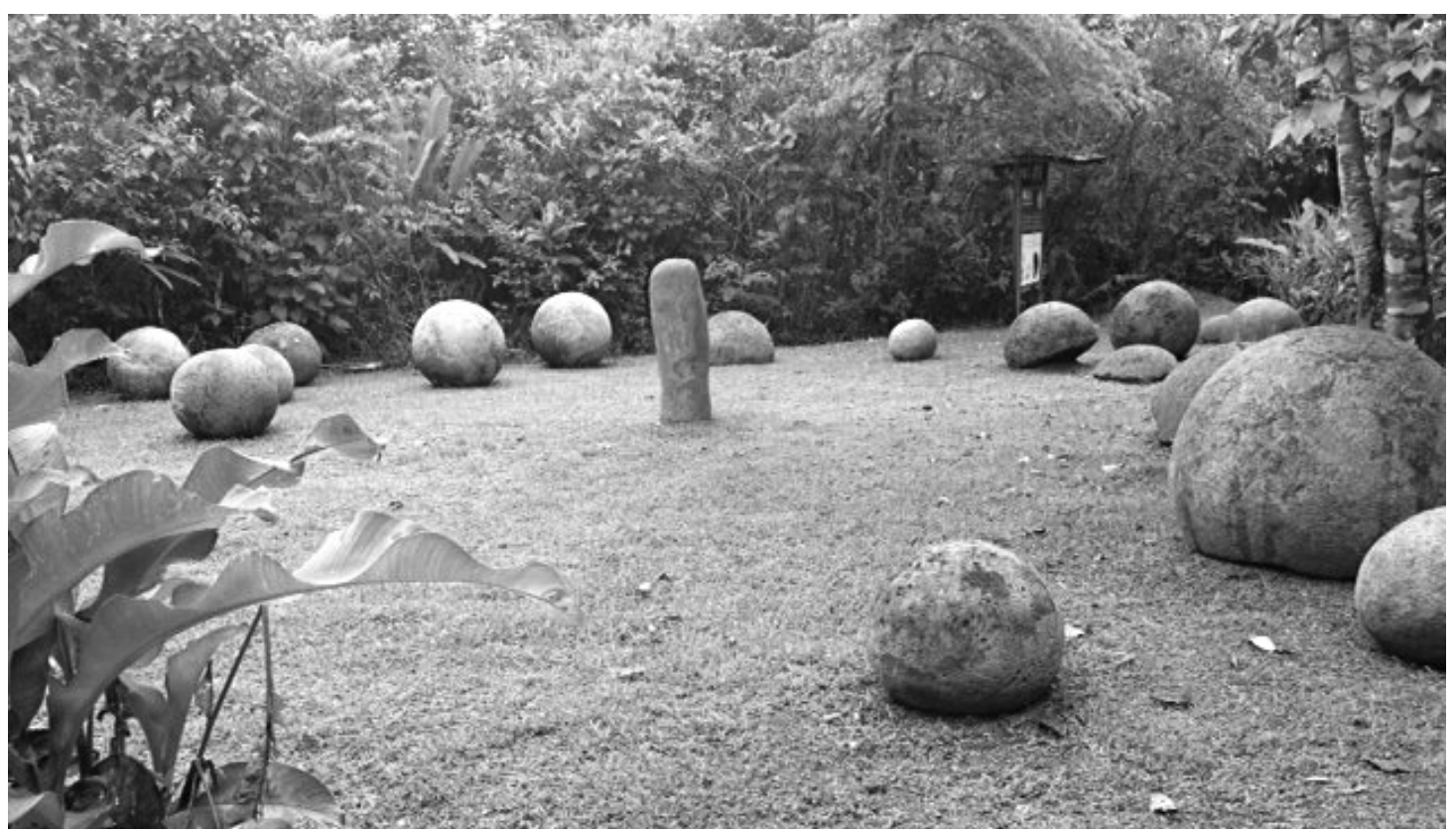

Figura. I Esferas en tránsito, Finca 6 
movimientos del poder no solo remiten a dominación sino siempre a resistencia. En la cultura como espacio simbólico en el cual se tejen relaciones de poder destaca la estética como discurso en torno al comportamiento sensible, lo bello y lo feo, lo permitido/prohibido, y las dinámicas que explican la particular construcción de "su mundo perceptual" que cada grupo social produce. En la aplicación de categorías estéticas y las instituciones que las vehiculizan, como por ejemplo "lo artístico", se teje la "astucia de la hegemonía", (al decir de Gramsci): la violencia simbólica que homogeneiza lo diverso, mediante la repetición e insistencia de versiones de la historia estética que ordenan, clasifican, producen invisibles, por exaltación y negación (Fernández y De Brasi, 1993, p. 80).

\section{Parte}

\section{El misterio y sus puestas en escena}

Las esferas precolombinas fueron descubiertas en la década de 1940 y se mantuvieron en una discreta marginalidad de objeto de escena decorativa de instituciones y residencias hasta muy recientemente. Son artefactos producidos por alguna de las culturas antiguas que poblaron el hoy territorio costarricense. Desde el punto de vista arqueológico, se las encuentra en la Región del Gran Chiriquí (que incluye la Zona Sur costarricense y atraviesa hasta parte del territorio panameño). Los hallazgos de esferas se concentran en un lugar: la Subregión del Diquís (Corrales, 2005, p. 3).

¿Por qué producen este artefacto en cantidades significativas con esa exclusiva localización? Este es el enigma que rodea de un inmenso atractivo reciente a esos objetos.

"En la vida de las formas pululan estos gigantes sin sentido, o con un sentido demasiado pequeño para un cuerpo tan grande, gigantes que solamente se pueden justificar infundiéndoles unos sentidos desmesurados". Umberto Eco (2005, p. 304)

Su significado se ha perdido. Son un misterio. Las esferas se han convertido en un tema cultural-estético con cierta popularidad de manera muy reciente, a partir de la explotación del valor comercial y político del misterio.
El misterio funciona como atractor y echa a rodar una diversidad de sentidos estrafalarios sin fundamento científico, en los que se desliza una simbólica propia del imaginario audiovisual hollywoodense: las esferas como portadoras de magnetismos energéticos que una prosapia de personajes famosos han experimentado, la especulación paranormal o extraterrestre (el millonario gurú de los misterios Von Daniken menciona las esferas ticas como producto de visitas de seres espaciales [Sibaja, 2004, p. 139]), paradoja de una época que se define como la cumbre de la razón científico-tecnológica. Nuestras esferas han dado para colocarse en el mismo estante especulativo de una estética "interestelar", con las pirámides egipcias o mayas, los petroglifos, monolitos y otros artefactos antiguos, explotados por resignificaciones que un mercado logra posicionar con altísimo consumo. La expansión de la industria turística en las últimas décadas es una nueva coyuntura en la que esta lectura comercial del misterio amenaza con imponerse:

El astrólogo español Vicente Cassanya llegó a Palmar Sur en una mañana de octubre del $201 \mathrm{l}$. Abrazó una de las esferas patrimoniales del parque y percibió una sensación hermosa. Estaba tan emocionado que impresionó al alcalde de Osa y el presidente municipal que casualmente pasaban por ahí. Hubo una conexión especial y en solo un rato de charla surgió la idea de organizar un congreso de cinco días en octubre con más de 2.000 personas para divulgar en el mundo las esferas precolombinas del valle de El Diquís y el valor místico que percibió Cassanya. (...) El Concejo Municipal tomó el 20 de marzo el acuerdo 297-2012 para nombrar a Cassanya "embajador" del cantón sureño y director ejecutivo de algo que bautizaron "Proyecto Esferas", basado en el patrimonio arqueológico nacional. (Murillo, 20I2)

Esta iniciativa ha logrado seducir a sectores de terratenientes y del gobierno local con la promesa del glamour que atraería visibilidad y negocios a una zona plagada de necesidades en que se tramita una mezcla del valor simbólico de un estatus de celebridad asociado a poseer millones o pertenecer a la farándula. En esta ocasión, las esferas entran en contacto con el poder de los medios masivos, creadores de modelos glamorosos de identidad y filantropía 
asociados a la generación de negocios usando como recurso el espectáculo de la imagen:

El mercadeo del proyecto se apoya en parte sobre millonarios como la española Carmen Cervera, baronesa Thyssen y dueña del museo homólogo,y de famosos como el artista imitador Julio Zavala. La española incluso anunció que vendrá y pagará a pintar el puente sobre el río Térraba, en la carretera Interamericana Sur. (...) Estas personalidades aportan imagen y dinero para el proyecto nutrido de filantropía, según su gestor en Costa Rica, el empresario Jorge Collado, oriundo y terrateniente en la zona sur. (...) "¡Ningún negocio! Bueno sí, pero para la gente de la zona sur, para los hoteles y la gente que podrá hospedar en sus casas a los extranjeros, en un mes en que ni las gallinas ponen", justificó Collado, quien aseguró que Proyecto Esferas "es municipal, no privado". (Murillo, 20 I2)

El deslizamiento del sentido misterioso que rodea estos productos estéticos antiguos al territorio de la fantasía no es en modo alguno inocuo. Refleja una construcción imaginaria que actúa despojando a sus productores humanos originales de la capacidad simbólica para crearlos y usarlos en su contexto cultural, e imponiéndoles la convención cultural mediática por proyección de sus categorías de espectacularidad. Se trata de una operación de descontextualización, que opera la violencia simbólica de secuestrar de su ámbito original estas producciones estéticas, y sus funciones sociales, cualesquiera que fueran. La inmediata reacción de las autoridades del Museo Nacional y la indignación por esa puesta en escena de instancias culturales locales lograron, en esta oportunidad, desestimular un proyecto que pretendía la visibilidad turística de los poderes "cósmicos" de las esferas.

\section{Avatares del Patrimonio}

Las luchas institucionales para contar con los recursos para el estudio y la protección de este patrimonio han requerido de una particular habilidad política para leer y sacar provecho de diversas coyunturas del poder nacionales e internacionales. Una auténtica tarea de resistencia se ha logrado afianzar con un titánico esfuerzo de profesionales de la arqueología como Francisco Corrales o Ifigenia Quintanilla, que han establecido alianzas con sectores locales organizados, movilizado recursos

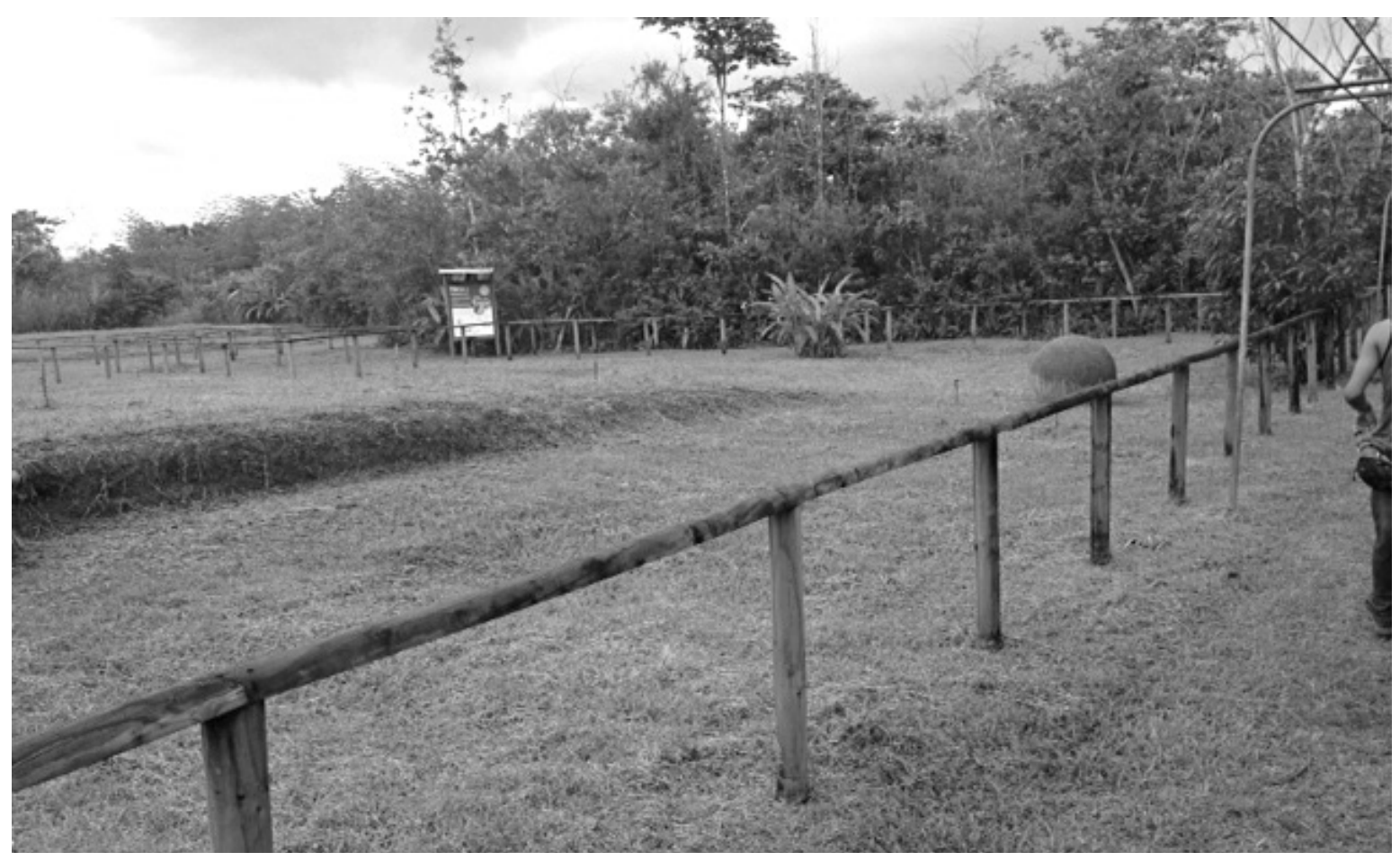

Figura 2. Sitio Finca 6 
privados de empresarios y fundaciones y que a la fecha han fructificado en la candidatura ante la UNESCO de las esferas como Patrimonio de la Humanidad. El camino ha sido largo y ha sido esencial la construcción progresiva de conocimiento y puesta en valor estético, en medio de las tramas de poder.

\section{Las esferas como símbolo nacional recientemente reconocido}

En un país que construyó su imaginario de nación en torno al mito de un origen "blanco-europeo-excepcional-democrático", según ha estudiado Jiménez (2008, pp. 250-259), los sectores hegemónicos promovieron un consenso efectivo basado en la negación de un pasado indígena y en la exclusión de los aportes de otros grupos culturales. La evidencia real de ese pasado, constituida por los objetos y hallazgos de seres difícilmente reconocidos como ancestros, ha requerido una labor crítica de ruptura con esa mitología, en un contexto en el que la antropología, los estudios culturales y la historiografía poscolonial han confrontado categorías occidentales y colonialistas como "arte primitivo" o "arte prehistórico", proponiendo que la complejidad y la producción estética son característica universal de todos los grupos humanos y rompiendo con las categorías evolucionistas binarias del poder: culturas atrasadas-culturas de progreso, tasadas por su desarrollo tecnológico, y convertido en media esencial de valor-poder de las comunidades humanas (Jenckes y Dove, 20 I 0, p. 104).

Hoy importantes museos de países poderosos cambian de nombre y las colecciones que acumularon para exhibición exótica de pueblos colonizados reciben otro tratamiento. Esta es una coyuntura que políticamente ha favorecido el reconocimiento de las esferas por sectores del poder. Las circunstancias han cambiado, las esferas se promueven como evidencia funcional para afirmación de lo nacional como poseedor de algo único y exclusivo. Es interesante que, a partir de las últimas décadas, en que se promueven con fuerza los procesos de integración centroamericana como agenda de democratización y consolidación regional, los gobiernos ticos han redescubierto las esferas como productos representativos de la cultura costarricense, como en el Pabellón Centroamericano de la Feria Internacional de Aichi en Japón 2005, o el siguiente anecdotario acerca de las política de promoción internacional del país:

Una esfera de piedra precolombina de Costa Rica está a punto de ser una de las atracciones más vistas del nuevo museo del Quai Branly en París, Francia. En el 2002 Ani Quirós fue designada como Embajadora de Costa Rica en Francia, y como ella misma dice "días antes de entrevistarme con el presidente Jacques Chirac se me vino un chispazo. Me habían dicho que la entrega de credenciales era muy formal y no se podía pedirle nada al presidente, pero a mí se me ocurrió ofrecer", recordó. En ese momento se le ocurrió que una esfera de piedra sería ideal, de inmediato llamó a Costa Rica y pidió los permisos respectivos. Cuando llegó la hora de su entrevista presentó sus credenciales y momentos antes de que finalizara su audiencia rompió el protocolo. "Le conté de la esfera al presidente y quedó fascinado, siguió hablando conmigo. A él se le olvidó que otros embajadores estaban esperando y me habló de las esferas, algo que conocía más que yo. Al día siguiente el director del nuevo museo me estaba llamando para empezar a concretar", añadió la señora Quirós.

Francisco Corrales, director del Museo Nacional, contraparte costarricense en el préstamo, explicó que se trata de un hecho de primera importancia que sólo es frecuente entre los grandes museos del mundo. Además añadió que el museo del Quai Branly rápidamente estará en los primeros lugares en el ránking de los museos mundiales. El museo es la gran obra del gobierno de Chirac, y por eso el interés que el propio presidente le dedica al tema. Para su creación se reunieron las colecciones de dos museos que pasaron a mejor vida, el Museo del Hombre y el Museo de Artes de África, Asia y Oceanía. Cuenta con 300 mil piezas en su colección y expondrán permanentemente 3500.

Acerca de las esferas, Corrales explica que se trata de utensilios realmente interesantes que identifican a lo que es hoy Costa Rica, único lugar del mundo donde existen esferas perfectas de piedra. "En otros países se encontraron objetos redondeados pero no en la cantidad y tamaños como los que aquí se encuentran, por eso el país va a figurar, va a llamar la atención en el museo y así se dará a conocer, la gente 
va a querer saber dónde está ese país de las esferas de piedra", explicó Francisco Corrales. (Molina, 2006)

Esta cita de un periódico nacional sintetiza la preciada exclusividad de las esferas como dotadoras de identidad: producir objetos únicos otorga reconocimiento de existencia en el mapa. ¿Se trata del mapa de quienes legitiman otras culturas? La institucionalidad cultural europea, representada en su museo, es cargada aquí de una investidura dadora de existencia, mediante su atención a los objetos de las culturas diversas no europeas, con connotación de originalidad. El objeto entra a escena como integrante del panorama cultural mundial, para que los ojos europeos confirmen su apropiación: un lugar para nuestras esferas es un intento político de lograr validación cultural mediante la legitimación de un producto estético desde quienes tienen poder de otorgar valor simbólico. Ese utilitario reconocimiento oficial del potencial de generación de sentido nacional del misterio lleva las esferas al diseño de los billetes y a prefigurar potenciales de explotación turística de lo que antes eran plantaciones bananeras. Progresivamente se desata el "furor esférico" oficial, y en buena hora, el resultado del juego permite que años de un trabajo científico tesonero tenga alguna oportunidad de resonancia, incluyendo un proyecto para la declaratoria como "Patrimonio Cultural de la Humanidad" ante la UNESCO. Para coronar este momento estelar, el escultor costarricense posicionado en Europa, Jorge Jiménez Deredia, promueve las esferas precolombinas como fundantes de su "simbolismo cósmico" y se constituye en autoridad que termina de legitimar un valor estético a las esferas. Señala Amoretti (2004) en el prólogo de su libro:

"para él la creación artística se genera de una correcta comprensión de la propia identidad cultural. Así, en el sustrato indígena de esa identidad encuentra un símbolo que, en su prístina desnudez, le muestra el sentido del ser y su existencia: las esferas de piedra esculpidas por el pueblo boruca".

No existe evidencia actual para asociar la cultura boruca con la producción de las esferas, como no sea su coincidencia en la región. Al parecer, una gran diversidad de pueblos y culturas se movieron en diferentes períodos por la zona y, entre ellas, solo una produce las esferas y, por los estudios de entierros y restos óseos, parece haber sido bastante endogámica según los hallazgos de Quintanilla (2004, p. 35). Tampoco en los descendientes actuales hay memoria o uso de las esferas y su significado. En síntesis, se trata de un discurso perdido. En el año 2009, el escultor instaló sus trabajos de inspiración esférica a lo largo y ancho del patrimonio arqueológico romano, lo cual es sin duda un hito de posicionamiento para un artista nacional. La paradoja de esta producción estética que se reconoce continuadora de las esferas es muy particular, mas no se pretende analizar este hecho más que como una referencia de un inusitado protagonismo esférico actual, y es probable que haya contribuido a categorizarlas como productos escultóricos.

"Si son redondas, dan vueltas. Hay que moverlas de aquí", el difícil comienzo en una plantación de banano y un evento que marcó la política cultural

La historia del reconocimiento de las esferas como productos estéticos tiene inicios bastante precarios: el hallazgo arqueológico en los años cuarenta fue realizado por peones bananeros que limpiaban terrenos para las plantaciones de la United Fruit Company. Gran parte de las esferas fueron removidas de su sitio original para dar lugar al banano y solo algunas fueron temporalmente concedidas al estudio de la arqueóloga norteamericana Doris Stone, por su amistad con el capataz a cargo de la obra, su coterráneo George P. Chittenden. En agradecimiento, la Dra. Stone registró como "descubridor" de las esferas a este funcionario de la "Yunai" en 1943 (Sibaja, 2004, p. 26). A partir de ese momento se da un auténtico carnaval que lleva a la moda de tener una esfera en el antejardín de las familias adineradas del país, así como de las instituciones públicas, e implica la venta, donación, traslado de las "bolas" y la pérdida significativa de la información acerca de su contexto cultural. La memoria local guarda la anécdota que titula este apartado, y las historias de oro y tesoros extraordinarios guardados en el interior de las "bolas", que llevó a la destrucción de algunas de ellas, con mazos y dinamita (Obando, 20।3). Aparte de la fragilidad de regulación para la conservación del patrimonio precolombino que es evidente en la época, que denota el imaginario nacional afirmado desde el "no tener un pasado indígena" (y justamente lo opuesto a la descrita como exaltación, como base identitaria de los últimos años), este elemento 


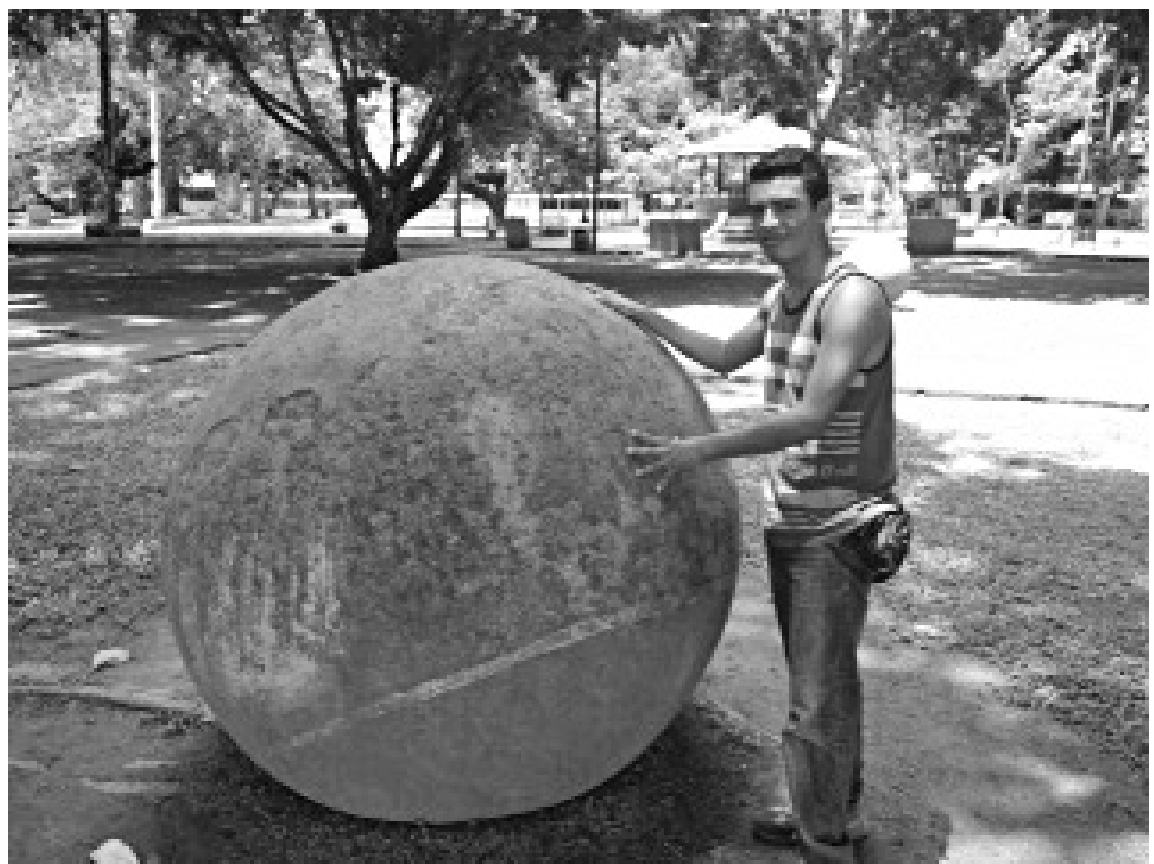

Figura 3. F. Obando en el Parque de Palmar Sur

llama la atención por los circuitos de acumulación y consumo de estos productos como signos de poder de sectores adinerados del país.

Este hecho no es exclusivo de las esferas: importantes colecciones de objetos precolombinos saqueados se convirtieron en símbolo de distinción, según el concepto de Bourdieu (20 I0), despojados de su contexto y convertidos en objetos exóticos decorativos y su comercio ilegal propiciado por redes internacionales han promovido la apropiación de estos productos estéticos como entretenimiento privado y acumulación de poderosos.

Cabe señalar que la historia de las esferas resulta un claro ejemplo de cómo un artefacto viaja por los tiempos como enunciador de distintos discursos adjudicados según intereses metaestéticos, políticos, económicos. Pero las esferas también guardan la otra cara de la moneda. Es en la plantación bananera y sus condiciones de enclave que la historia de la organización de los trabajadores costarricenses tiene una de sus más gloriosas páginas, reivindicando un discurso de justicia social y defensa nacional. En los años ochenta, la compañía bananera se aprestaba a un cambio operativo sustantivo, dejar la producción, costosa por las reivindicaciones sociales y las características operativas del monocultivo, para quedarse con la siempre ventajosa comercialización. Como respuesta a un intenso movimiento de huelga, la "Compañía" comunica su decisión de irse de la zona, dejando tras de sí incertidumbre y desempleo.

Obando (2013) relata en una entrevista que por esos mismos años, dos enormes esferas (de más de dos metros de diámetro) cuyo destino es ser colocadas en la recién construida Plaza de la Cultura en San José, son cargadas en un transporte que en su primer intento de partida no logra remontar la pendiente del cerro y debe volverse al punto de partida, las comunidades que parte el río Térraba en Palmar Norte y Palmar Sur. La comunidad no se queda como espectadora pasiva. Un movimiento social, protagonizado por estudiantes y profesores del Colegio Técnico, logra articular una respuesta social de gran movilización cuya arma principal es cerrar el tránsito por la carretera interamericana. Dos posturas de política cultural entran en conflicto: la oficial del gobierno y su Ministerio de Cultura, que argumenta que las esferas son patrimonio cultural nacional y no local y por tanto su destino es decisión de la institucionalidad, que dice proteger el interés nacional frente a la beligerancia de una conflictiva comunidad bananera, y la postura comunitaria: las esferas deben permanecer en el territorio en que se fabricaron, que también para eso tiene su "centro 


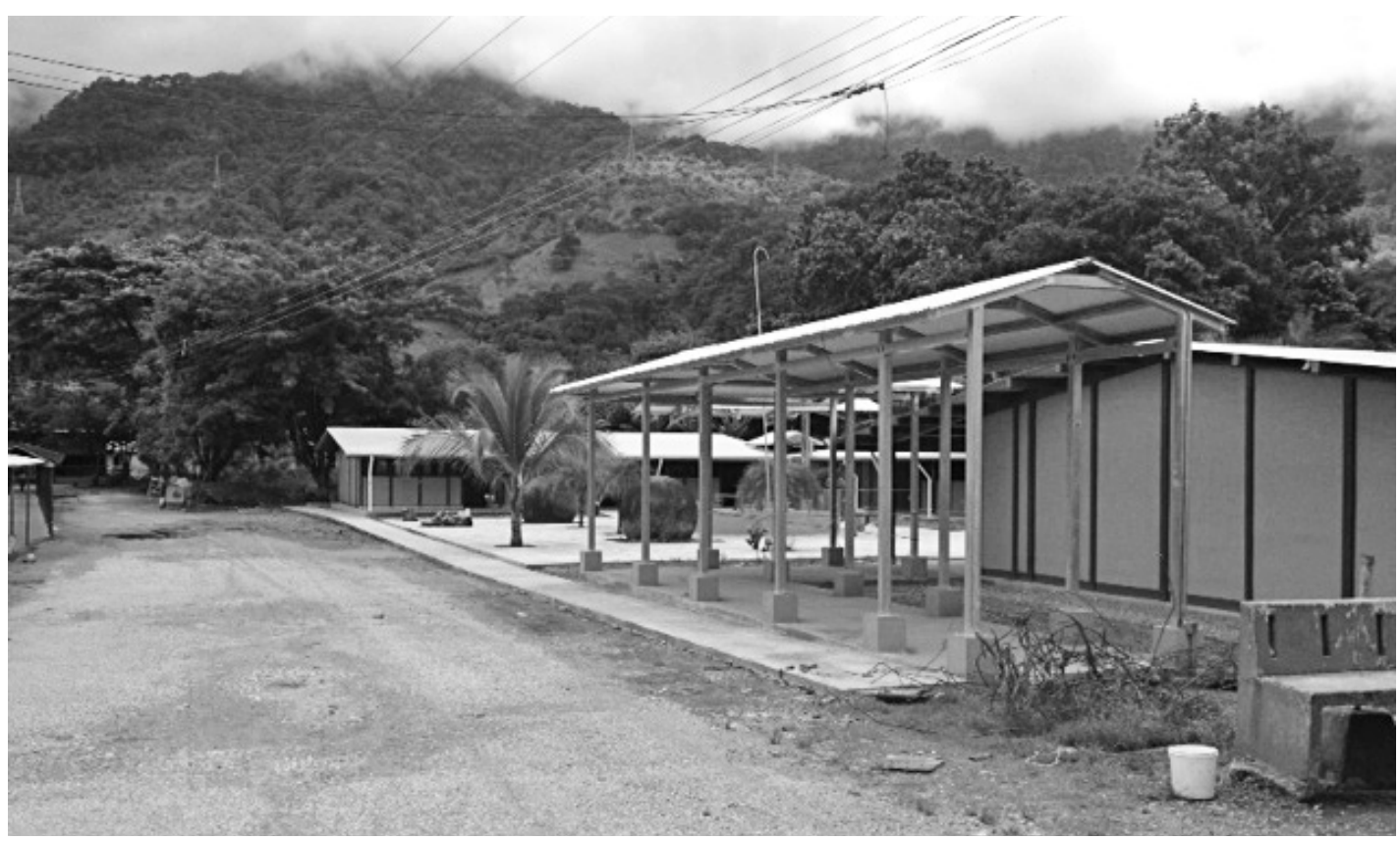

Figura 4. Esferas en el colegio

de cultura" el colegio, una respuesta de afirmación de dignidad contra el despojo acumulado. El triunfo de ese movimiento debe reconocerse como un hito que pondría en cuestionamiento el modelo centralizado en el Valle Central de la política cultural costarricense (Obando, 20I3).

En la actualidad, una fructífera alianza entre sectores organizados locales, en particular la cooperativa SurCoop, propietaria de Finca 6, que ha donado los terrenos, y profesionales del Museo Nacional cuya acción de resistencia se ha logrado afianzar institucionalmente, trabajan en el Proyecto Parque de las Esferas, en el único lugar que al momento contiene el hallazgo de esferas en su ubicación original. Se trata de un proyecto promisorio, por el hallazgo de vestigios de asentamientos que guardan valiosa información acerca de la cultura que las produjo, enterrados bajo sedimentos de las crecidas del río. No resulta sencilla la obtención de recursos para un manejo nacional, digno y que permita el estudio científico de este patrimonio, por lo que su reconocimiento como Patrimonio de la Humanidad sin duda es una iniciativa de política cultural afirmativa. Resistencia para contener poderosos intereses económicos que podrían haber convertido la zona en parque temático.

\section{Parte: Notas para un análisis estético}

El encuadre temporal

El primer aspecto a tomar en cuenta para el análisis estético de un objeto precolombino es la tarea deconstructiva (De la Campa, 20l0, p. 80) de su encuadre histórico cultural. Un discurso perdido es un vacío relevante para los modelos de la historia social que tienen como punto culminante la razón y la expresión verbal. Es una irritación, una molestia, un llamado, una fragilidad. Encubre esto la omnipotencia de encontrar fórmulas de desciframiento conquistador, que confía en razonar de determinada manera y ponerle nombre a las cosas como manera de "explicarlas". Ha sido un problema para la historia de la estética occidental generar categorías que den cuenta de la inmensa diversidad de objetos, prácticas, usos y sus funciones que pueden ser considerados artísticos. Esta circunstancia más que una excepción parece ser la regla en la historia de la estética cuando se abordan productos culturales remotos, como se advierte respecto del "arte" prehistórico o de culturas antiguas. La construcción de una historiografía de lo estético en que se fundamenta la historia del arte se evidencia como la invención de un discurso. Las características ideológicas de este discurso parecen ser la distorsión de la universalidad de la producción estética, transformada en una genética del ideal de progre- 
so de la cultura occidental y la instalación de un modelo evolutivo homogeneizador, que naturaliza la producción social de sentido que es la cultura. El resultado es una versión muy poderosa que explica la cultura humana como el camino lógico racional hacia la entronización y prevalencia de una cultura: la occidental. El tema del poder queda oculto. Toda la producción estética humana, compleja y diversa, es transformada en evidencia, que comprueba, corrobora este discurso. Los productos estéticos antiguos o diversos pasaron a ser evidencia de confirmación de evolución y superioridad cultural: de esos seres primitivos de pensamiento mágico connotados como ilusos no podría salir otra noción que la certidumbre de estar mejor que ellos en lo sucesivo, y agradecerlo a la evolución de la historia humana. Poderosos imperios como el que produce la cultura egipcia fueron adosados como "capítulos".

La herramienta central de la razón imponiendo este discurso es la organización de la historia de acuerdo a un cierto orden, que una vez que se instala, queda oculto. Para esto es necesario sin duda una acción selectiva: es muy probable que una serie de "evidencias" deban ser obviadas, ocultadas, para garantizar la coherencia del discurso. Se entiende así cómo la producción estética precolombina no está incorporada a la historia del arte. Acha (1993) propone renunciar a un "purismo indigenista", es decir, desde hoy el mestizo será un análisis interpretativo. Pero será posible que el mismo se emprenda como una deconstrucción crítica de esas versiones impuestas por el poder en la historia. Aplicar esta acción cuestionadora propone la ruptura en la esfera simbólica del poder.

\section{Perspectiva contextualizadora}

Se hace necesaria la relectura rigurosa e incluyente de los productos estéticos de las culturas antiguas de América desde una perspectiva contextualizadora, que parta del esfuerzo por comprender la lógica propia de sus vestigios en sí misma, y no desde el molde de la historiografía tradicional. Se trata de una decisión consciente por cuestionar cuáles son las fuerzas legitimadoras desde las que actúa la adjudicación del valor estético. Un aspecto central de esa relectura es la ruptura del modelo centro/periferia en que se inscribió la historia social humana.

Costa Rica ha sido, desde esa perspectiva, un marginal entre marginales; al no tener vestigios de grandes construcciones arquitectónicas o templos, entramos a la historia precolombina como no importantes respecto de los centros imperiales norte y sur de las culturas antiguas de América, los que a su vez son periferia de la cultura central europea. La producción estética del hoy territorio costarricense, reflejo de esa cultura "menor", solo tenía sentido como zona de tránsito, de encuentro de esos dos centros culturales. Las esferas "únicas" en la producción cultural precolombina y el sistema cultural que las produjo parecen apuntar a lo contrario: a un cierto aislamiento de estos pueblos, a una complejidad y persistencia propias (Quintanilla, 2004, p. 36).

De acuerdo con los estudios de esta autora, se considera el Diquís como "zona de influencia sudamericana", y los estudios genotípicos y dialectales de los pobladores actuales referencian un origenchibchoide, por lo que debe pensarse en largos períodos de tiempo que promueven un desarrollo cultural con características propias (en realidad, el poblamiento del mundo entero sigue ese patrón de lento movimiento-asentamiento). La proyección desde una perspectiva actual de un intenso y frecuente intercambio no resulta sostenible. Esto implica otra ruptura necesaria del enfoque: la presuposición de un modelo evolucionista hacia el avance y el progreso, que instala una sola línea de continuidad y de interacción con los centros de poder. Desde esa ruptura es posible prefigurar otros ritmos, otros caminos, todos legítimos por sí mismos y no atrasados respecto de_otros y, por qué no, una cierta independencia cultural, es decir, la producción estética se presenta como incomparable por ser consustancial a la construcción de una cultura. Nos puede atraer o no, la podemos relacionar con otras o no, pero instalar un valor en función de culturas ajenas es inadmisible e impone. Es cierto que parece haber constantes y coincidencias en la historia cultural, pero es la diferencia entre culturas la clave para desmitificar la historia misma.

\section{Reconstrucción interpretativa}

Quintanilla (2004, 2007), mediante un estudio ecológico y cultural de las esferas, se pregunta acerca de cuál era el sentido de producirlas y su posible lugar de consumo y circulación como producto cultural, para aproximarse a su carácter estético en tanto expresión simbólica ritual. Establece una producción de esferas de larga duración, por unos 1000 años, que tiene su inicio en el período Aguas Buenas, data- 
do entre el 400 DC y el 800 DC y continúa en un período siguiente que va del 800 DC hasta la llegada de los españoles alrededor de I500 DC en que se extingue por completo. Lo peculiar es su restricción geográfica en el Delta del Diquís. Se han documentado alrededor de 200 esferas que van desde los 2.5 $\mathrm{m}$ de diámetro hasta los $30 \mathrm{~cm}$. Pero su promedio ronda $1.5 \mathrm{~m}$. Fabricar y colocar durante tantos años estos monolitos colosales da cuenta de su notable importancia para esa cultura, su restricción espacial puede estar asociada a una función de reforzamiento de etnicidad, de pertenencia y diferenciación colectivas (Quintanilla, 2004, pp. 9- 10).

A partir de 500 DC, las excavaciones muestran un proceso de complejización de la organización social, de una sociedad tribal a cacicazgos con función redistribuidora, que luego funcionan como confederaciones cuya producción se especializa y complementa, dada la evidencia escultórica antropomorfa de guerreros armados en guerras de control y reorganización territorial. Las esferas se producen y consumen en un contexto de diversificación de elementos arquitectónicos: los asentamientos mostraron un aumento de población, con construcciones diferenciadas en su interior que podían tener hasta 30 metros de diámetro por 3 metros de altura, calculados por los montículos que constituyeron sus basamentos. Hay espacios públicos, evidenciados en plazas, suelos empedrados, sistemas de caminos, muros de protección. Las esferas parecen haber sido elementos monumentales instalados para el consumo público, dispuestas en alineamientos y conjuntos en espacios abiertos (Quintanilla, 2004, pp. 30-35). No se ha logrado establecer evidencia de las hipótesis que postulan representaciones astronómicas.

\section{Desclasificar}

La ruptura con la historiografía tradicional implica el cuestionamiento de las clasificaciones y patrones con que se organiza la historia de la estética. Será posible pensar en un período clásico pobre o en la sencillez coexistente con un barroquismo ornamental. Esta ruptura parte de un desmoldamiento y una abierta decisión por comprender OTRAS estéticas y por establecer la coexistencia de diversidades estilísticas predominantes y antagónicas. De alguna manera, la historia del arte y su consumo actual es evidencia de eso, y de la fragilidad de las argumentaciones legitimadoras.
De lo anterior se deriva otro cuestionamiento necesario relacionado con las categorías estéticas con que se pondera un producto como "arte". ¿Esas esculturas esféricas que un pueblo produjo durante mil años son arte u objetos arqueológicos? Lo reconocido como artístico está ligado a las categorías estéticas legitimadoras de una institucionalidad cultural. En el trabajo canónico de Ferrero (1977) sobre la Costa Rica precolombina, las esferas tienen una muy discreta mención en el capítulo de Etnohistoria (p. 172) y una total ausencia en el capítulo sobre Estética y el "Precolombino: arte deslumbrante". Se evidencia lo planteado sobre su reciente reconocimiento como producto con valor estético. Su retórica de reiteración está lejos de la categoría de originalidad y, a pesar de que no se ha logrado encontrar vestigios de los lugares o herramientas de fabricación, al parecer se está frente a un código simbólico construido con una función comunicacional, por grupos humanos artesanales especializados que desarrollan un virtuosismo que probablemente implica labor colectiva de producción, propia de taller para transmisión de códigos formales a partir de los cuales prácticamente no hay mucha preponderancia de la expresión singular o personal del fabricante, sino en la adscripción a un sistema de trabajo y a una forma que reta su dominio.

\section{Poner en diálogo con otros objetos}

Si se integra a esta perspectiva la consideración de otros objetos producidos por la misma cultura, valores como la originalidad y los patrones de diseño se expresan a partir de variaciones de prototipos, por ejemplo, de la escultórica animal en figuras de espiga, los barriles tallados, las lozas funerarias, las extraordinarias mesas ceremoniales y figurillas en oro constituyen variaciones en tamaño, detalles, de códigos reiterados. La maestría en el tallado en piedra figurativo o en el vaciado de oro reflejan poca importancia de registrar la autoría y sí de mostrar el dominio de la techné como búsqueda de un camino de expresión simbólica. También se denota diversidad de producción estética: para consumo individual con función de ornamentación en el oro, mientras que en el trabajo en piedra hay escultórica ritual probablemente de consumo colectivo y en no pocos casos ligado a objetos funcionales como metates, mesas, bancos. 
En estas coordenadas es fundamental no aislar los objetos esfera de los otros productos estéticos de esa cultura, por lo que un abordaje de sistema puede iluminar más para descubrir una producción compleja, diversa, que trasciende una dimensión funcional y se complementa con un discurso que propone una interpretación (aunque no sabemos cuál en el caso de las esferas), una conciencia estética que se vehiculiza en apropiación/reproducción/ adscripción de expresiones simbólicas. La creatividad formal, la generación de significados originales o la autonomía de las funciones prácticas con que se define un arte de artistas individuales, desarrollado con fines explícitos de disfrute según ciertos códigos de legitimación que implican competencias (propios de la producción artística de Occidente a partir del Renacimiento según reseña Gombrich (1984), deben en este caso ceder ante el poder expresivo, unificador, de una esfera perfecta reiterada en medio de un asentamiento en un bosque lluvioso.

\section{La práctica estética como producción social}

El vacío de una gramática para entenderlo puede llevar a especulaciones sin rumbo siguiendo a Shiner (2004, pp. I19-4I5): pudo ser un arte en serie, arte religioso, arte oficial, ser el sello de diseño arquitectónico, un elemento escenográfico con valor de signo, o art tool desde alguna perspectiva ritual. ¿Cómo caracterizar esas invenciones humanas como arte? Se trata de un tema ideológico, ya que implica una asignación de sentido: "la historia, en su vitalidad voraz, vacía y llena las formas, las priva y dota de significado", señala Eco (2005, p. 304). Una vez más depende de si nos adscribimos a la expresión de novedad formal o de contenido, cuyo efecto "incita a nuevas actitudes artístico-culturales" según Acha (1993, p. 196).

La representación estilizada y abstracta que coexiste con el desarrollo de otros lenguajes simbólicos con figuración también estilizada en animalística y figuras antropomorfas, hacen pensar en una cultura que no conocía el término arte, pero invertía extraordinarias energías en su producción estética; baste señalar que ninguno de sus asentamientos se ubicó en función de la disponibilidad de la roca granítica que era trabajada en el sitio de yacimiento, para luego ser rodada a su destino, lo que implicaba un esfuerzo de transporte de $15 \mathrm{~km}$ ○ más, tarea también indudablemente colectiva. Es significativo que la esfera más grande hasta ahora encontrada no fuera colocada en el espacio más visible ni en el asentamiento más grande. Con sus 2,54 metros de diámetro y 16 toneladas de peso, se la ubica en una ladera, lo que sugiere patrones diversos o cambiantes de ubicación o distribución, probablemente ligados a un sentido de conmemoración o sacralidad especial (Quintanilla, 2007, p. 92).

Aparte del tamaño y la ubicación, otro aspecto de singularización de las esferas fue la diversidad de acabados, logrados mediante el uso de abrasivos logrando diferentes texturas de superficie: las básicas, en las que se aprecian muescas del golpeteo de fabricación, otras de superficie alisada o finamente alisadas y otras con un trabajo de pulido hasta un acabado brillante. En unas pocas $(n=10)$ se logran apreciar decoraciones de petroglifos mediante incisiones en la piedra, que pueden o no ser contemporáneas a su producción (Quintanilla, 2007, p. 106).

\section{A manera de cierre}

Silenciosas, siguen hablando. Fueron hechas con esa intencionalidad contundente: su material es piedra sólida capaz de emerger de la selva, la tierra y el olvido. Su forma es a la vez síntesis abstracta y volumen geométrico. Son únicas, pero hay muchas, iguales, de distintos tamaños. La fabricación y uso de las esferas como esculturas públicas fue expresión material de una serie de ideas relacionadas con el concepto de esfericidad que se repiten idénticas por siglos. Esto hace pensar en artefactos para indicar de manera perdurable una evocación, un recurso de memoria, que probablemente fue preciso y concreto para sus consumidores. La concentración restringida a una ubicación regional implica una fabricación destinada al consumo interno: no circulaban fuera de su particular ubicación, no obstante, al interior de ésta pudieron haber sido fijas o cambiar de lugar... Artefactos que comunican algo, cuyo reto técnico y de organización del trabajo colectivo implica una decisión social de alta inversión de energía, lo que lleva a pensar en su gran valor de posesión y reproducción como objeto simbólico cuya gramática se ha perdido. Los estudios arqueológicos dan cuenta de una organización social compleja que pudo tener en su imaginario distintas funciones de comunicación, como la pertenencia, la identidad. Hoy el discurso perdido tiene guardados ambos potenciales de resignificación: desde la dominación o desde la resistencia. 


\section{Bibliografía}

Acha, J. (1993). Las culturas estéticas de América Latina. México: Universidad Autónoma de México.

Agamben, G. (2003). Infancia e historia. Argentina: Anda Hidalgo Editora.

Amoretti, M. (2004). Prólogo en: Jiménez Deredia, J. Génesis. Puente de luz. Disponible en: www.deredia.com/Books/ Deredia_PUENTE.pdf (Consultado julio 20 I 3)

Araujo, N. (20 I 0). Cultura. En: Szurmuk, M. \& Mckee, I. Diccionario de Estudios Culturales Latinoamericanos. (pp.7|-74). México: Siglo XXI Editores.

Barasch, M. (1996) Teorías del arte. Madrid: Alianza.

Baudrillard, J. (1979). Crítica de la economía política del signo. México: Siglo XXI Editores.

Bayer, R. (1993). Historia de la estética. México: Fondo de Cultura Económica.

Benjamín, W. (20।0). Ensayos Escogidos. Buenos Aires: El cuenco de plata, teoría y ensayo.

Bourdieu, P. (20।0). El sentido social del gusto, elementos para una sociología de la cultura. Argentina: Siglo XXI Editores.

Corrales, F. \& Badilla, A. (2005). El Paisaje Cultural: Delta del Diquís. San José, Colección Museo Nacional, UNESCO.

De la Campa, R. (20 I0). Deconstruccionismo. En: Szurmuk, M. \& Mckee, I. Diccionario de Estudios Culturales Latinoamericanos. (pp. 75-80). México: Siglo XXI Editores.

Eco, U. (2005). La estructura ausente. Barcelona: Ed. Lumen.

Fernández, A.M. \& De Brasi, J.C (comp.). (1993). Tiempo histórico y campo grupal. Buenos Aires: Ed. Nueva Visión.

Ferrero, L. (1977). Costa Rica Precolombina. San José: Editorial Costa Rica.

Fonseca C., M.E. (2006). Esferas precolombinas entre el deterioro y la conservación. Revista de ciencia y tecnología Crisol, No16, pp. 50-52.

Foucault, M. (1976). Microfísica del poder. Madrid: Ed. La Piqueta.

García Canclini, N. (2005a). Diferentes, desiguales y desconectados, mapas de la interculturalidad. España: Gedisa.

García Canclini, N. (2005b). Culturas híbridas. Estrategias para entrar y salir de la modernidad. Argentina: Paidós.
Gombrich, E.H. (1984). Estudios sobre el arte del renacimiento. Madrid: Alianza.

Jenckes, K. \& Dove, P. (20 I0). Estética. En: Szurmuk, M. \& Mckee, I. Diccionario de Estudios Culturales Latinoamericanos. (pp. I 01 105). México: Siglo XXI Editores.

Jiménez, A. (2008). El imposible país de los filósofos. San José: Editorial Universidad de Costa Rica.

Jiménez, J. (2005). Las raíces del arte: el arte etnológico. En: Ramírez, J.A. (dir.) \& Gómez Cedillo, A. (coord.). Historia del arte.Vol. I. Alianza Editorial.

Lukács, G. (1982). Estética I: La peculiaridad de lo estético. Vol I. Barcelona: Grijalbo.

Molina Bustos, M. (2006, junio 10). Esfera de piedra es protagonista en París. La Prensa libre. Disponible en: http:// www.prensalibre.co.cr/2006/junio// 0/abanico01.php>. (Consultado en junio 2009)

Murillo, A. (2012, julio 23). Municipio de Osa da a astrólogo español proyecto de esferas ticas. La Nación. Disponible en <http://www.nacion.com/20 I 2-07-23/ElPais/municipio-deosa-da-a--astrologo-espanol-proyecto-de-esferas-ticas-.aspx (Consultado julio 2009)

Obando, F. (20 I3). Entrevista personal realizada por la autora el 2-3 julio de 2013 en Sierpe y Proyecto Esferas. Palmar Sur, Zona Sur, Costa Rica.

Olmos, R. (2005). El mundo antiguo. En: Ramírez, J.A. (dir.) \& Gómez Cedillo, A. (coord.). Historia del arte l. 8va ed. Madrid: Alianza Editorial.

Paz, O. (1977). "El arte de México: materia y sentido". Prólogo al catálogo de la Exposición de Arte Mexicano en Madrid. En: Los privilegios de la vista. México: Fondo de Cultura Económica.

Quintanilla, I. (2004). Las esferas de piedra del Pacífico Sur de Costa Rica: Descifrando el enigma desde la arqueología. Trabajo de Tesis de Doctorado en Arqueología prehistórica, Universidad de Barcelona.

Quintanilla, I. (2007). Esferas precolombinas de Costa Rica. San José: Fundación de Museos del Banco Central.Shiner, L. (2004). La invención del arte. Barcelona: Ed. Paidós Ibérica S.A.

Sibaja, A. (2004). Esferas de piedra de Costa Rica (Enigma en el Delta del Diquís). San José: Imp. Punto Gráfico. 